\title{
Highly Enantioselective Iridium-Catalyzed Hydrogenation of 2-Aryl Allyl Phthalimides.
}

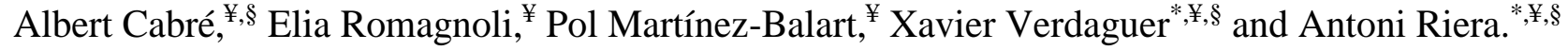 \\ ${ }^{\sharp}$ Institute for Research in Biomedicine (IRB Barcelona), The Barcelona Institute of Science and Technology (BIST). Baldiri \\ Reixac 10, 08028 Barcelona, Spain. \\ ${ }^{\S}$ Departament de Química Inorgànica i Orgànica, Secció Orgànica. Facultat de Química, Universitat de Barcelona. Martí i \\ Franquès 1, Barcelona E-08028, Spain.
}

\section{Supporting Information Placeholder}

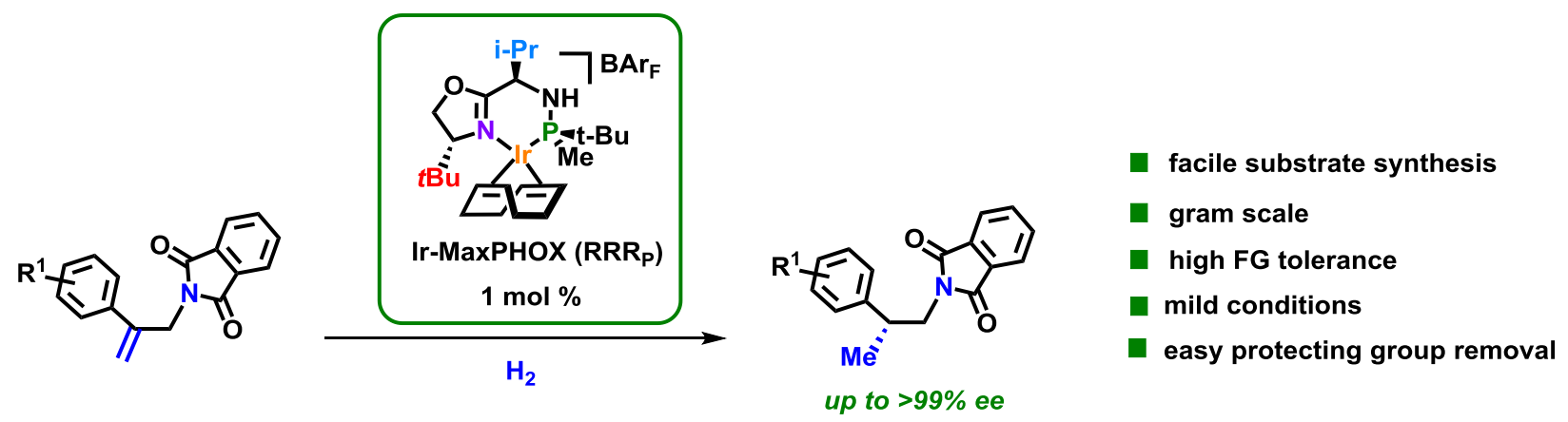

\begin{abstract}
The iridium-catalyzed asymmetric hydrogenation of 2-aryl allyl phthalimides to afford enantioenriched $\beta$-aryl- $\beta$-methyl amines is presented. Recently developed Ir-MaxPHOX catalysts are used for this enantioselective transformation. The mild reaction conditions and the feasible removal of the phthalimido group makes this catalytic method easily scalable and of great interest to afford chiral amines. The importance of this new methodology is exemplified by the formal synthesis of $(R)$-Lorcaserin, OTS514 and enantiomerically enriched 3-methyl indolines.
\end{abstract}

The biological activity of many pharmaceutical compounds and agrochemicals is intrinsically related to their absolute molecular configuration. ${ }^{1}$ The asymmetric synthesis of chiral compounds is, therefore, an essential field in organic chemistry. In particular, chiral $\beta$-aryl propanamines are extremely interesting candidates as precursors of pharmaceuticals and active molecules. ${ }^{2}$ For example, Lorcaserin, an anorectic drug that has been typically synthesized by chiral resolution; ${ }^{3}$ OTS514, a marketed inhibitor of a serinethreonine kinase that is often overexpressed and transactivated in several types of cancer; ${ }^{4}$ or LY-392098, a potent positive allosteric modulator of 2-amino-3-(5-methyl-3-hydroxyisoxazol-4-yl)-propanoic acid (AMPA) receptor. ${ }^{5}$ Moreover, we can envision the synthesis of several drug intermediates such as 3-methylindolines in few steps from $\beta$-aryl propanamines (Figure 1).

Among the strategies to obtain enantioenriched $\beta$-aryl propanamines, catalytic asymmetric hydrogenation provides one of the most practical and powerful approaches due to its operational simplicity, high reactivity and atom economy. ${ }^{6}$ However, most of the syntheses found in the literature are performed by means of chiral resolution or by using stoichiometric agents. ${ }^{7}$ To the best of our knowledge, there are only few examples in which enantioenriched $\beta$-aryl propanamines can be obtained by metal-catalyzed enantioselective hydrogenation. ${ }^{8}$ In 2005, Zhang and co-workers reported the asymmetric hydrogenation of 2-alkyl allyl phthalimides using a $\mathrm{Ru}_{-} \mathrm{C}_{3}$-tunephos catalyst. ${ }^{8 \mathrm{a}}$ However, the scope of this reaction was focused on alkyl groups and the single example of 2-aryl allyl phthalimide gave only $55 \%$ ee of the corresponding $\beta$-methylpropanamine. More recently, our group reported the hydrogenation of $N$-sulfonyl allyl amines using the iridium complex of Pfaltz's catalyst Ubaphox. ${ }^{8 \mathrm{~d}}$

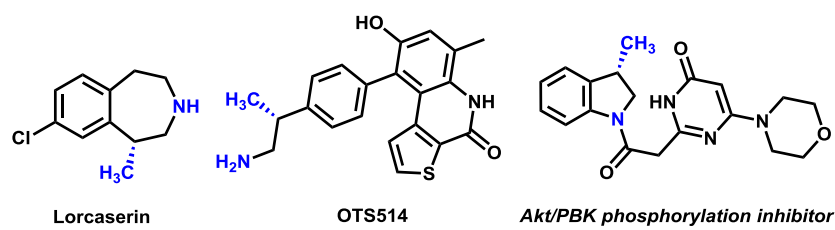

Figure 1. Examples of biologically active compounds containing a chiral $\beta$-methyl amine.

Iridium complexes bearing chiral $\mathrm{P}, \mathrm{N}$ ligands ${ }^{9}$ have been successfully applied in the asymmetric hydrogenation of a wide range of unfunctionalized or minimally functionalized olefins. ${ }^{10}$ Our group has developed several P-stereogenic chiral ligands. ${ }^{11} \mathrm{Re}-$ cently, we designed a family of $\mathrm{P}, \mathrm{N}$-ligands (MaxPHOX) that were coordinated to iridium. ${ }^{12}$ These catalysts can be obtained from protected tert-butyl methyl phosphinous acid and commercially available amino acids and amino alcohols. These iridium complexes have three chiral centers, so up to four diastereoisomers (catalysts 
1-4, Figure 2) can be obtained. Moreover, the substituent of the oxazoline ring can be easily modified. This variety of structures facilitates the fine-tuning of the catalyst. This strategy has allowed us to find an excellent catalyst for the enantioselective hydrogenation of cyclic enamides $^{12 \mathrm{a}}, \mathrm{N}$-aryl ${ }^{12 \mathrm{~b}}$ and $\mathrm{N}$-alkyl ${ }^{12 \mathrm{c}}$ imines. Moreover, these catalysts also proved to be extremely efficient in the isomerization of cyclic allyl carbamates, yielding high levels of enantioselectivity. ${ }^{12 \mathrm{~d}}$

Here, we present the asymmetric hydrogenation of $\mathrm{N}$ phthalimido 2-phenyl allyl amines using an Ir-MaxPHOX catalyst to obtain chiral $\beta$-methyl amines. It is worth noting that, in this occasion, the best catalyst of the family (2c) had not been described. To showcase the applicability of this reaction, the formal enantioselective synthesis of several biologically active compounds was performed.

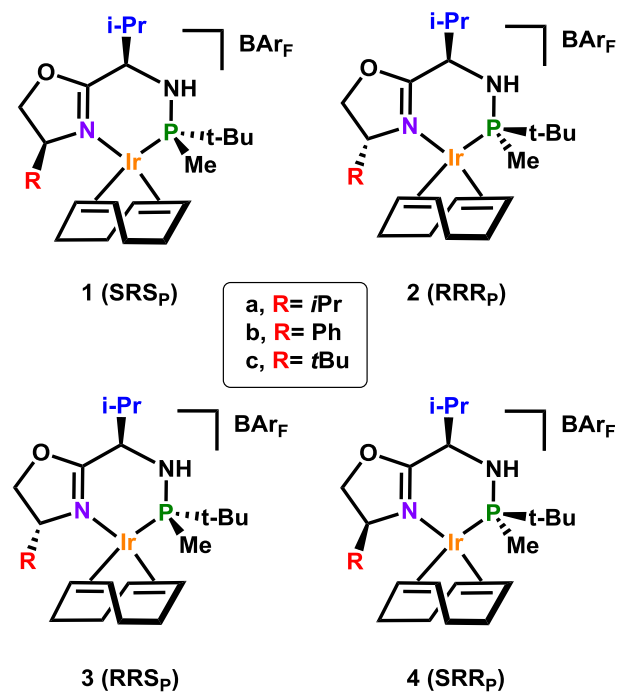

Figure 2. Ir-MaxPHOX family of catalysts.

On the basis of our studies, $N$-phthalimido 2-phenyl allyl amine (5a), which is easily synthesized in three steps from acetophenone (see Supporting Info), was used as model substrate. The family of Ir-MaxPHOX catalysts was then used for the asymmetric hydrogenation of $5 \mathbf{a}$ to afford chiral amine $\mathbf{6 a}$ (Table 1). The standard conditions of the reaction were as follows: dichloromethane as solvent, 1 bar of $\mathrm{H}_{2}$ pressure and stirring overnight. The Ir-MaxPHOX catalysts with an isopropyl in the oxazoline ring 1-4a were first tested (Table 1, entries 1-4). All of them showed full conversion to $\mathbf{6 a}$. In particular, catalyst $\mathbf{2 a}$ gave the best ee ( $64 \%$ ee, Table 1 , entry 2$)$. Of note is the huge difference between the catalysts in terms of chiral induction achieved by simply modifying the relative configuration of their chiral centers. We then modified the oxazoline substituent of 2 into an aromatic group, such as phenyl (2b) or bulkier group such as tert-butyl (2c). In the first case, the reactivity was not affected but the enantioselectivity was substantially improved (Table 1, entry 5). With 2c, the enantiomeric excess was enhanced up to $90 \%$ without affecting the conversion (Table 1, entry 6). The synthesis of this ligand is described in the Supporting information. Then we studied the effect of the hydrogen pressure: when increased to 50 barG the enantioselectivity was not affected (Table 1, entry 7). Finally, catalyst loading was decreased to $1 \mathrm{~mol} \%$ and a solvent screening was performed at 1 bar of $\mathrm{H}_{2}$. With dichloromethane the conversion after $12 \mathrm{~h}$ was still complete (Table 1, entry 8); in contrast, with ethyl acetate or THF the reactivity decreased to $60 \%$ and $5 \%$, respectively
(Table 1, entries 9 and 10). Using dichloromethane the reaction temperature could be decreased to $-20{ }^{\circ} \mathrm{C}$, affording $6 \mathbf{a}$ with an excellent $98 \%$ ee and full conversion (Table 1, entry 11 ).

A mechanistic study of this reaction using $\mathrm{D}_{2}$ revealed that the hydrogenation occurred exclusively to the allylic bond and that there was no prior isomerization to the corresponding enamide (see Supporting Information).

Table 1. Catalyst screening and optimization of the asymmetric hydrogenation of 2-(2-phenylallyl)isoindoline-1,3-dione 5a. ${ }^{[a]}$
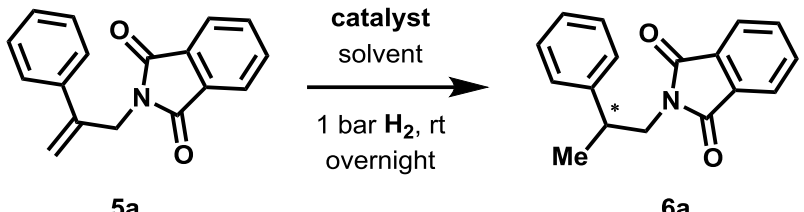

$6 a$

$\begin{array}{cccccc}\text { entry } & \text { catalyst } & \text { loading } & \text { solvent } & \begin{array}{c}\text { conv. } \\ (\%)^{[\mathrm{b}]}\end{array} & \text { ee }(\%)^{[\mathrm{c}]} \\ 1 & 1 \mathrm{a} & 5 \mathrm{~mol} \% & \mathrm{CH}_{2} \mathrm{Cl}_{2} & >99 & 6(S) \\ 2 & 2 \mathrm{a} & 5 \mathrm{~mol} \% & \mathrm{CH}_{2} \mathrm{Cl}_{2} & >99 & 64(R) \\ 3 & 3 \mathrm{a} & 5 \mathrm{~mol} \% & \mathrm{CH}_{2} \mathrm{Cl}_{2} & >99 & 20(S) \\ 4 & 4 \mathrm{a} & 5 \mathrm{~mol} \% & \mathrm{CH}_{2} \mathrm{Cl}_{2} & >99 & 32(R) \\ 5 & 2 \mathrm{~b} & 5 \mathrm{~mol} \% & \mathrm{CH}_{2} \mathrm{Cl}_{2} & >99 & 69(R) \\ 6 & 2 \mathrm{c} & 5 \mathrm{~mol} \% & \mathrm{CH}_{2} \mathrm{Cl}_{2} & >99 & 90(R) \\ 7^{[\mathrm{d}]} & 2 \mathrm{c} & 5 \mathrm{~mol} \% & \mathrm{CH}_{2} \mathrm{Cl}_{2} & >99 & 89(R) \\ 8 & 2 \mathrm{c} & 1 \mathrm{~mol} \% & \mathrm{CH}_{2} \mathrm{Cl}_{2} & >99 & 90(R) \\ 9 & 2 \mathrm{c} & 1 \mathrm{~mol} \% & \mathrm{EtOAc}^{2} & 60 & 89(R) \\ 10 & 2 \mathrm{c} & 1 \mathrm{~mol} \% & \mathrm{THF}^{2} & 5 & \text { n.d. } \\ 11^{[\mathrm{e}]} & 2 \mathrm{c} & 1 \mathrm{~mol} \% & \mathrm{CH}_{2} \mathrm{Cl}_{2} & >99 & \mathbf{9 8}(R) \\ & & & & & (96)^{[\mathrm{f}]}\end{array}$

[a] See Supporting Information for experimental details. Reactions were run in a pressure reactor at $1 \mathrm{bar}^{\mathrm{G}}$ of $\mathrm{H}_{2}$ pressure. ${ }^{[b]}$ Determined by ${ }^{1} \mathrm{H}$ NMR. ${ }^{[\mathrm{c}]}$ Measured by chiral HPLC. ${ }^{[\mathrm{d}]}$ Reaction was performed at 50 bar of $\mathrm{H}_{2}$. ${ }^{[\mathrm{e}]}$ Reaction was performed at $-20{ }^{\circ} \mathrm{C}$. ${ }^{[\mathrm{f}]}$ Isolated yield.

With the optimal conditions in hand, we studied the scope of the reaction. As seen in Scheme 1, halide-substituted aryl groups were well-tolerated, with excellent enantioselectivities in all cases (6b to $6 \mathbf{e}$, Scheme 1). The catalyst loading for the substrates with bromine $(\mathbf{5 d})$ and iodine $(\mathbf{5 e})$ had to be increased to $2 \mathrm{~mol} \%$ to ensure full conversion. Electron-donating substituents such as methyl (6f) or isobutyl (6m) gave $97 \%$ and $98 \%$ ee respectively (Scheme 1). We then expanded the substrates to meta-substituted aryl groups. Again, and using only $1 \mathrm{~mol} \%$ of catalyst 2c, chiral amines $\mathbf{6 g}$ and $\mathbf{6 h}$ were afforded with excellent enantioselectivities. The asymmetric hydrogenation orthosubstituted compounds (5i-k) also gave excellent enantiomeric excesses except in the case of the methoxy substituent $(\mathbf{6 i})$ that decreased to $83 \%$ ee. Finally, an allyl amine with another aryl substituent such as a naphthyl (5l) also afforded the corresponding amine $\mathbf{6 1}$ in $97 \%$ ee. 
Scheme 1. Scope of the catalytic hydrogenation. ${ }^{\text {[a] }}$

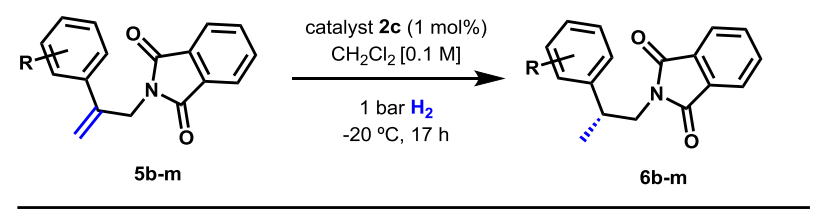

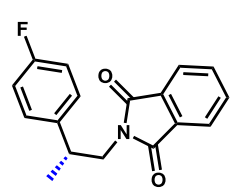

6b, $97 \%$ yield $>99 \%$ ee

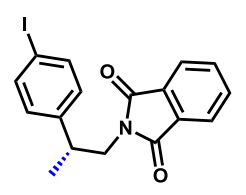

$6 \mathrm{e}^{[\mathrm{b}]}, 99 \%$ yield $98 \%$ ee

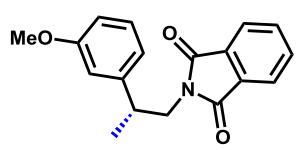

$6 \mathrm{~h}, 90 \%$ yield $98 \%$ ee
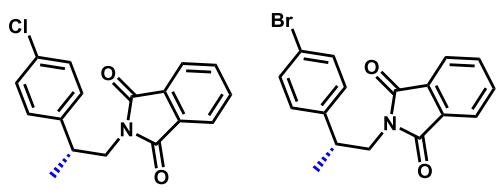

6c, $93 \%$ yield

$6 \mathbf{d}^{[\mathrm{b}]}, 99 \%$ yield

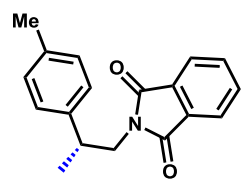
$\mathbf{6 f}, 91 \%$ yield
$\mathbf{9 7 \%}$ ee
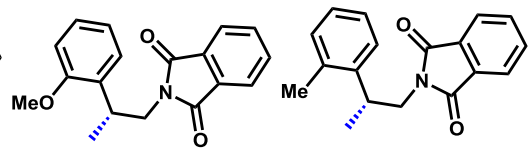
$6 \mathbf{6 i}, 99 \%$ yield
$83 \%$ ee

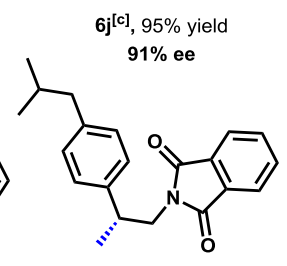

$\mathbf{6 k}^{[\mathrm{b}]}, 99 \%$ yield $90 \%$ ee

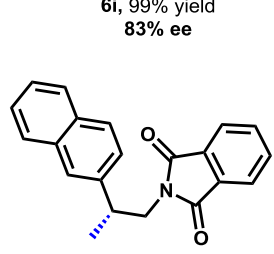

6 I, $89 \%$ yield $97 \%$ ee

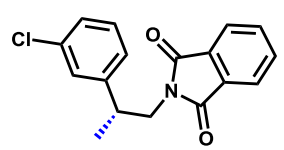

$6 \mathrm{~g}, 94 \%$ yield $98 \%$ ee

$6 \mathrm{~m}, 96 \%$ yield $98 \%$ ee [a] See Supporting Information for experimental details. Reactions were run in a pressure reactor at $1 \mathrm{bar}$ of $\mathrm{H}_{2}$ pressure. The reaction showed full conversion for all the examples. Enantiomeric excess was measured by chiral HPLC. ${ }^{[b]} 2$ mol \% of catalyst $2 \mathrm{c}$ was used. [c] $3 \mathrm{~mol} \%$ of catalyst $\mathbf{2 c}$ was used.

To showcase the applicability of our methodology, here we disclose a novel, short and efficient synthesis of $(R)$-Lorcaserin, 8 (Scheme 2). We performed a gram scale enantioselective synthesis of $\mathbf{6 g}$ applying our optimal conditions and decreasing the catalyst loading to $0.5 \mathrm{~mol} \%$. The compound $\mathbf{6 g}$ was achieved with an excellent $98 \%$ ee without recrystallization. Next, we deprotected the phthalimido group with hydrazine in toluene to afford 7 in excellent yield (93\%). To the best of our knowledge, this is the most efficient catalytic enantioselective synthesis of intermediate 7 , a direct precursor of $(R)$-Lorcaserin $(\mathbf{8}) .{ }^{13}$

The importance of the methodology developed here can also be appreciated by using $\mathbf{6 d}$ in the formal synthesis of OTS514 (10) (Scheme 3). The enantioenriched phathalimide 6d was deprotected by ethanolamine at reflux and protected as tert-butyl carbamate. The resulting $N$-Boc amine 9 is a known precursor of $\mathbf{1 0} .^{4 a}$
Scheme 2. Formal synthesis of $(R)$-Lorcaserin, 8.
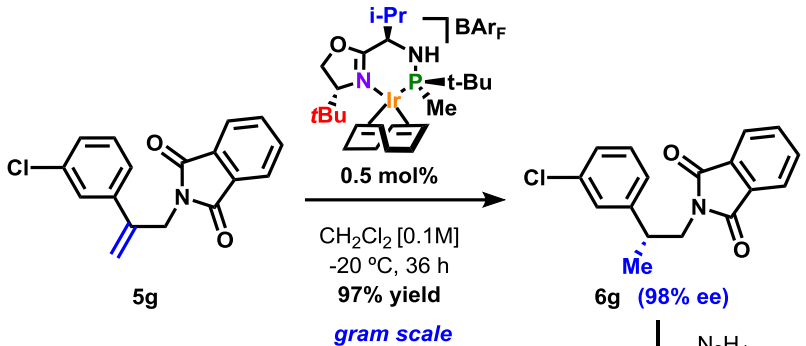

$6 \mathrm{~g}(98 \%$ ee $)$

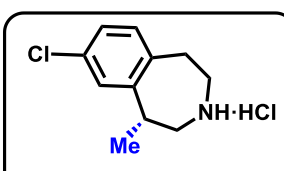

R)-Lorcaserin (8)

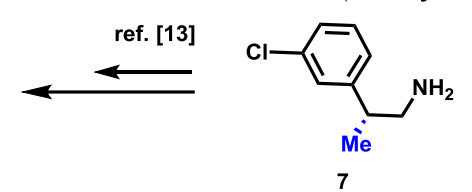

Scheme 3. Formal synthesis of OTS514, 10.
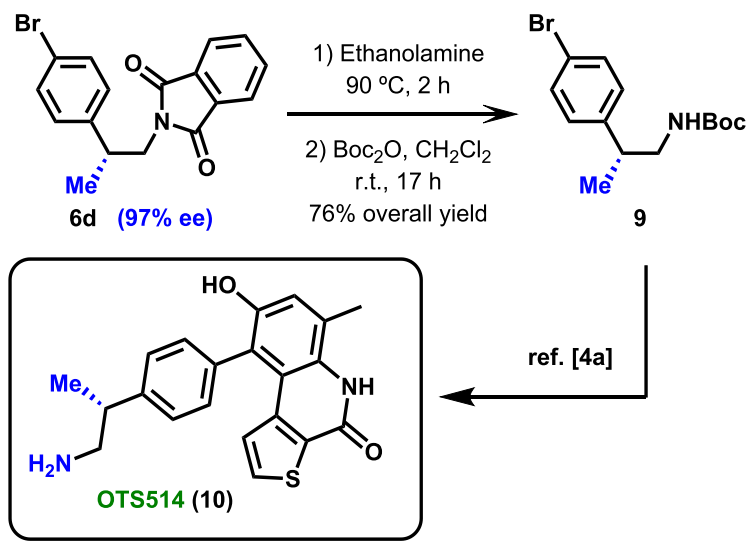

ref. [4a]

Finally, the chiral amines prepared here can be used in the synthesis of 3-methyl indolines. ${ }^{14}$ These compounds are relevant precursors of a number of biologically active compounds and natural products such as Duocarmycins, ${ }^{14 a, 15}$ the potent cytotoxic drug (+)-CC1065 ${ }^{14 a, 16}$ and the Akt/PBK phosphorylation inhibitor 12, ${ }^{17}$ currently in clinical phases. Thus, 3-methyl indoline 11 was readily prepared from amine 6k (Scheme 4) by phthalimido deprotection followed by copper-catalyzed intramolecular Ullmann-type amination. ${ }^{18}$

Scheme 4. Enantioselective synthesis of 3-methyl indoline 11.

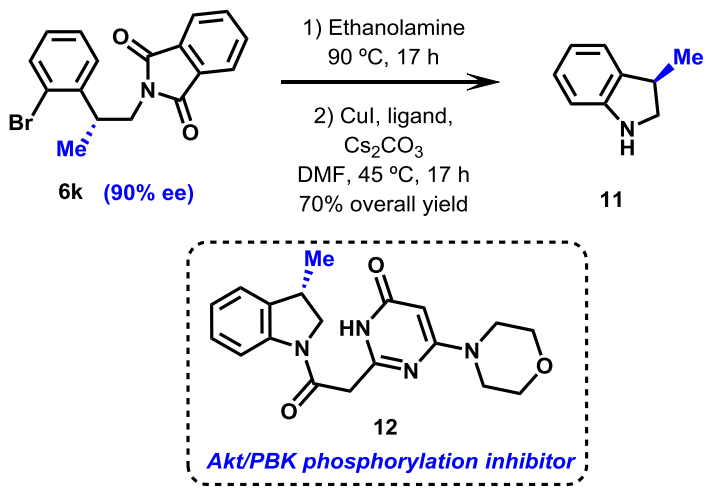


In summary, we have described a very efficient enantioselective synthesis of $\beta$-aryl propanamines by means of iridium-catalyzed asymmetric hydrogenation of $N$-phthalimido 2-aryl propanamines using the Ir-MaxPHOX complex 2c. Excellent enantiomeric excess values were obtained for wide range of compounds (up to 13 examples) using low catalyst loading and low hydrogen pressure. Several direct synthetic applications of this novel and effective catalytic method have been disclosed such as a formal synthesis of $(R)$-Lorcaserin and OTS514, as well as a novel approach to enantiomerically enriched 3-methyl indolines.

\section{ASSOCIATED CONTENT}

\section{Supporting Information}

Experimental procedure for the preparation of catalyst 2c. Experimental procedures, ${ }^{1} \mathrm{H}$ NMR and ${ }^{13} \mathrm{C}$ NMR spectra for all new compounds. The Supporting Information is available free of charge on the ACS Publications website.

\section{AUTHOR INFORMATION}

\section{Corresponding Authors}

antoni.riera@irbbarcelona.org and xavier.verdaguer@irbbarcelona.org.

\section{ORCID}

Albert Cabré: 0000-0001-5256-8798

Xavier Verdaguer: 0000-0002-9229-969X

Antoni Riera: 0000-0001-7142-7675

\section{Notes}

The authors declare no competing financial interests.

\section{ACKNOWLEDGMENT}

We gratefully acknowledge institutional funding from the Spanish Ministry of Economy, Industry and Competitiveness (MINECO, CTQ2017-87840-P) through the Centres of Excellence Severo Ochoa award, and IRB Barcelona from the CERCA Programme of the Catalan Government. A.C. thanks MINECO for a predoctoral FPU fellowship.

\section{REFERENCES}

(1) (a) Lin, G.-Q.; Zhang, J.-G.; Cheng, J.-F., Overview of chirality and chiral drugs. In Chiral Drugs, John Wiley \& Sons, Inc.2011; pp 3-28. (b) Ferrer, C.; Verdaguer, X.; Riera, A., Recent advances in the metal-catalyzed stereoselective synthesis of biologically active molecules. In Catalytic Methods in Asymmetric Synthesis, John Wiley \& Sons, Inc.2011; pp 625-670.

(2) (a) Omura, S. Macrolide Antibiotics, Academic Press, Orlando, FL, 1984. (b) Lazarevski, G.; Kobrehel, G.; Metelko, B.; Duddeck, H. Ring Opening Reactions of 6-Deoxy- 9-deoxo-9aaza-9a-homoerythromycin A 6,9-Cyclic Imino Ether. J. Antibiot. 1996, 49, 1066-1069. (c) Nicholas, G. M.; Molinski, T. F. Structures of Cribochalines A and B, Branched-Chain Methoxylaminoalkyl Pyridines from the Micronesian Sponge, Cribochalina Sp. Absolute Configuration and Enantiomeric Purity of Related O-Methyl Oximes. Tetrahedron 2000, 56, 2921-2927. (d) Davies, H. M. L.; Ni, A. Enantioselective Synthesis of $\beta$-Amino Esters and Its Application to the Synthesis of the Enantiomers of the Antidepressant Venlafaxine. Chem. Commun. 2006, 3110-3112. (e) Iii, R. N. H.; Stabler, R. S.; Repke, D. B.; Kress, J. M.; Walker, K. A.; Martin, R. S.; Brothers, J. M.; Ilnicka, M.; Lee, S. W.; Mirzadegan, T.
Highly Potent, Non-Basic 5-HT 6 Ligands . Site Mutagenesis Evidence for a Second Binding Mode at 5-HT6 for Antagonism. Bioorg. Med. Chem. Lett. 2010, 20 (11), 3436-3440. (f) Ramesh, P.; Suman, D. Asymmetric Synthetic Strategies of $(R)-(-)$-Baclofen : An Antispastic Drug. Synlett 2018, 50, 211-226.

(3) For the chemistry and biology of Lorcaserin, see: (a) Smith, B. M.; Smith, J. M.; Tsai, J. H.; Schultz, J. A.; Gilson, C. A.; Estrada, S. A.; Chen, R. R.; Park, D. M.; Prieto, E. B.; Gallardo, C. S.; Sengupta, D.; Dosa, P. I.; Covel, J. A.; Ren, A.; Webb, R. R.; Beeley, N. R. A.; Martin, M.; Morgan, M.; Espitia, S.; Saldana, H. R.; Bjenning, C.; Whelan, K. T.; Grottick, A. J.; Menzaghi, F.; Thomsen, W. J. Discovery and Structure - Activity Relationship of (1R)-8-Chloro-2,3,4,5-Tetrahydro-1-Methyl-1H-3-Benzazpine (Lorcaserin), a Selective Serotonin 5-HT 2C Receptor Agonist for the Treatment of Obesity. J. Med. Chem. 2008, 51, 305-313. (b) Nikolic, D.; Toth, P. P.; Ferlita, A.; Bartolo, V. D.; Montalto, G.; Banach, M.; Rizzo, M. Novel anti-obesity drugs and plasma lipids. Clinc. Lipidol. 2014, 9, 179.

(4) (a) Nakamura, Y.; Matsuo, Y.; Hisada, S.; Walker, J. R.; Decornez, H.; Gurram, M. (OncoTherapy Science, Inc., Japan). Preparation of thieno[2,3-c] quinoline derivatives as PKB inhibitors for treating cancer. PCT/US2011/030278. October 6, 2011. WO 2011/123419. (b) Park, J. H.; Chung, S.; Matsuo, Y.; Nakamura, Y. Development of Small Molecular Compounds Targeting Cancer Stem Cells. Med. Chem. Commun. 2017, 8 (1), 73-80. (c) Park, J. H.; Inoue, H.; Kato, T.; Zewde, M.; Miyamoto, T.; Matsuo, Y.; Salgia, R.; Nakamura, Y. TOPK (T-LAK Cell-Originated Protein Kinase) Inhibitor Exhibits Growth Suppressive Effect on Small Cell Lung Cancer. Cancer Sci. 2017, 108 (3), 488-496.

(5) (a) Li, X.; Tizzano, J. P.; Griffey, K.; Clay, M.; Lindstrom, T.; Skolnick, P. Antidepressant-like Actions of an AMPA Receptor Potentiator (LY392098). Neuropharmacology 2001, 40 (8), 1028-1033. (b) Ornstein, P. L.; Zimmerman, D. M.; Arnold, M. B.; Bleisch, T. J.; Cantrell, B.; Simon, R.; Zarrinmayeh, H.; Baker, S. R.; Gates, M.; Tizzano, J. P. Biarylpropylsulfonamides as Novel, Potent Potentiators of 2-Amino-3-(5-Methyl-3Hydroxyisoxazol-4-yl)-Propanoic Acid (AMPA) Receptors. $J$. Med. Chem. 2000, 43, 4354-4358. (c) Jones, N.; Neill, M. J. O.; Tricklebank, M.; Libri, V.; Williams, S. C. R. Examining the Neural Targets of the AMPA Receptor Potentiator LY404187 in the Rat Brain Using Pharmacological Magnetic Resonance Imaging. Psychopharmacology 2005, 180, 743-751.

(6) (a) Catalytic Asymmetric Synthesis, $2^{\text {nd }}$ ed.; Ojima, I.; Ed.; Wiley-VCH: Weinheim, 2000. (b) Applied Homogeneous Catalysis with Organometallic Compounds, $2^{\text {nd }}$ ed.; Cornils, B., Herrmann, W. A., Eds.; Wiley-VCH: Weinheim, 2002. (c) Asymmetric Catalysis on Industrial Scale: Challenges, Approaches and Solutions. Blaser, H. U., Schmidt, E., Eds.; Wiley-VCH: Weinheim, 2004. (d) Noyori, R. Asymmetric Catalysis : Science and Opportunities. Angew. Chem. Int. Ed. 2002, 41, 2008-2022.

(7) Recent selected examples: (a) Chem, A. J.; Xu, B.; Su, C. J.; Wang, C. J.; Zhou, G. C. A Concise Synthesis of Racemic Lorcaserin. Aust. J. Chem 2016, 69, 770-774. (b) Gini, A.; Bamberger, J.; Luis-Barrera, J.; Zurro, M.; Mas-Ballesté, R.; Alemán, J.; Mancheño, O. G. Synthesis of 3-Benzazepines by Metal-Free Oxidative $\mathrm{C}-\mathrm{H}$ Bond Functionalization-Ring Expansion Tandem Reaction. Adv. Synth. Catal. 2016, 358 (24), 4049-4056. (c) Zhu, Q.; Wang, J.; Bian, X.; Zhang, L.; Wei, P.; Xu, Y. Novel Synthesis of Antiobesity Drug Lorcaserin Hydrochloride. Org. Process Res. Dev. 2015, 19, 6-10.

(8) (a) Wang, C.; Sun, X.; Zhang, X. Enantioselective Hydrogenation of Allylphthalimides: An Efficient Method for the Synthesis of $\beta$-Methyl Chiral Amines. Angew. Chem. Int. Ed. 2005 , 44, 4933-4935. (b) Sun, X.; Zhou, L.; Li, W.; Zhang, X. Convenient Divergent Strategy for the Synthesis of TunePhos-Type Chiral Diphosphine Ligands and Their Applications in Highly Enantioselective Ru-Catalyzed Hydrogenations. J. Org. Chem. 2008, 73 (3), 
1143-1146. (c) Steinhuebel, D. P.; Krska, S. W.; Alorati, A.; Baxter, J. M.; Belyk, K.; Bishop, B.; Palucki, M.; Sun, Y.; Davies, I. W. Asymmetric Hydrogenation of Protected Allylic Amines. Org. Lett. 2010, 12 (18), 4201-4203. (d) Cabre, A.; Verdaguer, X.; Riera, A., Enantioselective Synthesis of $\beta$-Methyl Amines via Iridium-Catalyzed Asymmetric Hydrogenation of $N$-Sulfonyl Allyl Amines. Adv. Synth. Catal. 2019, 361, 4196-4200.

(9) (a) Pfaltz, A.; Blankenstein, J.; Hilgraf, R.; Hörmann, E.; Mcintyre, S.; Menges, F.; Schönleber, M.; Smidt, S. P.; Bettina, W.; Zimmermann, N. Iridium-Catalyzed Enantioselective Hydrogenation of Olefins. Adv. Synth. Catal. 2003, 345, 33-43. (b) Verendel, J. J.; Pàmies, O.; Diéguez, M.; Andersson, P. G. Asymmetric Hydrogenation of Olefins Using Chiral Crabtree-Type Catalysts : Scope and Limitations. Chem. Rev. 2014, 114, 2130-2169. (c) Müller, M. A.; Gruber, S.; Pfaltz, A. Recovery and Recycling of Chiral Iridium (N,P Ligand) Catalysts from Hydrogenation Reactions. Adv. Synth. Catal. 2018, 360 (7), 1340-1345. (d) Lu, W. J.; Chen, Y. W.; Hou, X. L. Highly Enantioselective Iridium-Catalyzed Hydrogenation of Trisubstituted Olefins, A, $\beta$-Unsaturated Ketones and Imines with Chiral Benzylic Substituted P,N Ligands Adv. Synth. Catal. 2010, 352 (1), 103-107. (e) Trifonova, A.; Diesen, J. S.; Chapman, C. J.; Andersson, P. G. Application of Phosphino-Oxazoline Ligands in Ir-Catalyzed Asymmetric Hydrogenation of Acyclic Aromatic N -Aryl Imines. Org. Lett. 2004, 6 (21), 3825-3827. (f) Li, J.-Q.; Liu, J.; Krajangsri, S.; Chumnanvej, N.; Singh, T.; Andersson, P. G. Asymmetric Hydrogenation of Allylic Alcohols Using Ir-N,P-Complexes. ACS Catal. 2016, 6 (12), 8342-8349.

(10) (a) Roseblade, S. J.; Pfaltz, A. Iridium-Catalyzed Asymmetric Hydrogenation of Olefins Initial Studies: An Unexpected Anion Effect. Acc. Chem. Res. 2007, 40, 1402-1411. (b) McIntyre, S.; Hörmann, E.; Menges, F.; Smidt, S. P.; Pfaltz, A. Iridium-Catalyzed Enantioselective Hydrogenation of Terminal Alkenes. Adv. Synth. Catal. 2005, 347 (2-3), 282-288. (c) Mazuela, J.; Verendel, J. J.; Coll, M.; Bo, A.; Marcel, C. Iridium Phosphite - Oxazoline Catalysts for the Highly Enantioselective Hydrogenation of Terminal Alkenes. J. Am. Chem. Soc. 2009, 131, 12344-12353. (d) Pàmies, O.; Andersson, P. G. Asymmetric Hydrogenation of Minimally Functionalised Terminal Olefins : An Alternative Sustainable and Direct Strategy for Preparing Enantioenriched Hydrocarbons. Chem. Eur. J. 2010, 16, 14232-14240. (e) Woodmansee, D. H.; Pfaltz, A. Asymmetric Hydrogenation of Alkenes Lacking Coordinating Groups. Chem. Commun. 2011, 47 (28), 7912-7916. (f) Mazuela, J.; Pàmies, O. Expanded Scope of the Asymmetric Hydrogenation of Minimally Functionalized Olefins Catalyzed by Iridium Complexes with Phosphite - Thiazoline Ligands. ChemCatChem 2013, 5, 2410-2417 (g) Patureau, F. W.; Worch, C.; Siegler, M. A.; Spek, A. L.; Bolm, C.; Reek, J. N. H., SIAPhos: Phosphorylated Sulfonimidamides and their Use in Iridium-Catalyzed Asymmetric Hydrogenations of Sterically Hindered Cyclic Enamides. Adv. Synth. Catal. 2012, 354, 59-64.

(11) (a) Cristóbal-Lecina, E.; Etayo, P.; Doran, S.; Revés, M.; Martín-Gago, P.; Grabulosa, A.; Costantino, A. R.; Vidal-Ferran, A.; Riera, A.; Verdaguer, X. MaxPHOS Ligand: PH/NH Tautomerism and Rhodium-Catalyzed Asymmetric Hydrogenations. Adv. Synth. Catal. 2014, 356 (4), 795-804. (b) Orgué, S.; Flores-Gaspar, A.; Biosca, M.; Pàmies, O.; Diéguez, M.; Riera, A.; Verdaguer, X. Stereospecific SN2@P Reactions: Novel Access to Bulky P-Stereogenic Ligands. Chem. Commun. 2015, 51 (99), 17548-17551. (c) Salomó, E.; Orgué, S.; Riera, A.; Verdaguer, X. Efficient Preparation of (S)- and (R)- Tert -Butylmethylphosphine-Borane: A Novel Entry to Important P-Stereogenic Ligands. Synthesis 2016, 48 (16), 2659-2663. (d) Prades, A.; Núñez-Pertíñez, S.; Riera, A.; Verdaguer, X. P-Stereogenic Bisphosphines with a Hydrazine Backbone: From N-N Atropoisomerism to Double Nitrogen Inversion. Chem. Commun. 2017, 53 (33), 4605-4608. (e) Salomó, E.; Prades, A.; Riera, A.; Verdaguer, X. Dialkylammonium tert-Butylmethylphosphinites: Stable Intermediates for the Synthesis of $\mathrm{P}$ Stereogenic Ligands. J. Org. Chem. 2017, 82 (13), 7065-7069. (f)
Téllez, J.; Gallen, A.; Ferrer, J.; Lahoz, F. J.; García-Orduña, P.; Riera, A.; Verdaguer, X.; Carmona, D.; Grabulosa, A. Half-Sandwich Complexes of $\operatorname{Ir}(\mathrm{III}), \mathrm{Rh}(\mathrm{III})$ and $\mathrm{Ru}(\mathrm{II})$ with the MaxPhos Ligand: Metal Centred Chirality and Cyclometallation. Dalt. Trans. 2017, 46 (45), 15865-15874. (g) Gallen, A.; Orgué, S.; Muller, G.; Escudero-Adán, E. C.; Riera, A.; Verdaguer, X.; Grabulosa, A. Synthesis and Coordination Chemistry of Enantiopure: tertBuMeP(O)H. Dalt. Trans. 2018, 47 (15), 5366-5379.

(12) (a) Salomó, E.; Orgué, S.; Riera, A.; Verdaguer, X. Highly Enantioselective Iridium-Catalyzed Hydrogenation of Cyclic Enamides. Angew. Chem. Int. Ed. 2016, 55 (28), 7988-7992. (b) Salomó, E.; Rojo, P.; Hernández-Lladó, P.; Riera, A.; Verdaguer, X. P-Stereogenic and Non-P-Stereogenic Ir-MaxPHOX in the Asymmetric Hydrogenation of N -Aryl Imines. Isolation and X-Ray Analysis of Imine Iridacycles. J. Org. Chem. 2018, 83 (8), 4618-4627. (c) Salomó, E.; Gallen, A.; Sciortino, G.; Ujaque, G.; Grabulosa, A.; Lledós, A.; Riera, A.; Verdaguer, X. Direct Asymmetric Hydrogenation of N-Methyl and N-Alkyl Imines with an Ir(III)H Catalyst. J. Am. Chem. Soc. 2018, 140 (49), 16967-16970. (d) Cabré, A.; Khaizourane, H.; Garçon, M.; Verdaguer, X.; Riera, A. Total Synthesis of (R)-Sarkomycin Methyl Ester via Regioselective Intermolecular Pauson-Khand Reaction and Iridium-Catalyzed Asymmetric Isomerization. Org. Lett. 2018, 20 (13), 3953-3957. (e) Biosca, M.; Salomó, E.; De La CruzSánchez, P.; Riera, A.; Verdaguer, X.; Pàmies, O.; Diéguez, M. Extending the Substrate Scope in the Hydrogenation of Unfunctionalized Tetrasubstituted Olefins with Ir-P Stereogenic Aminophosphine-Oxazoline Catalysts. Org. Lett. 2019, 21 (3), 807-811.

(13) Smilovic, I. G.; Cluzeau, J.; Richter, F.; Nerdinger, S.; Schreiner, E.; Laus, G.; Schottenberger, H. Synthesis of Enantiopure Antiobesity Drug Lorcaserin. Bioorg. Med. Chem. 2018, 26 (9), 2686-2690.

(14) (a) Boger, D. L.; Boyce, C. W.; Garbaccio, R. M.; Goldberg, J. A. CC-1065 and the Duocarmycins: Synthetic Studies. Chem. Rev. 1997, 97 (3), 787-828. (b) Kuwano, R.; Kaneda, K.; Ito, T.; Sato, K.; Kurokawa, T.; Ito, Y. Highly Enantioselective Synthesis of Chiral 3-Substituted Indolines by Catalytic Asymmetric Hydrogenation of Indoles. Org. Lett. 2004, 6 (13), 2213-2215. (c) Groth, U.; Köttgen, P.; Langenbach, P.; Lindenmaier, A.; Schütz, T.; Wiegand, M. Enantioselective Synthesis of 3,3-Disubstituted Indolines via Asymmetric Intramolecular Carbolithiation in the Presence of (-)-Sparteine 1. Synlett 2008, No. 9, 1301-1304. (d) Sieber, J. D.; Rivalti, D.; Herbage, M. A.; Masters, J. T.; Fandrick, K. R.; Fandrick, D. R.; Haddad, N.; Lee, H.; Yee, N. K.; Gupton, B. F.; Senanayake, C. H. Rh-Catalysed Asymmetric Conjugate Addition of Boronic Acids to Nitroalkenes Employing a: P Chiral P, $\pi$-Hybrid Ligand. Org. Chem. Front. 2016, 3 (9), 11491153.

(15) Yamada, K.; Kurokawa, T.; Tokuyama, H.; Fukuyama, T. Total Synthesis of the Duocarmycins. J. Am. Chem. Soc. 2003, 125 (22), 6630-6631.

(16) Glennon, R. A. Central Serotonin Receptors as Targets for Drug Research. J. Med. Chem. 1987, 30 (1), 1-12.

(17) Certal, V.; Carry, J. C.; Halley, F.; Virone-Oddos, A.; Thompson, F.; Filoche-Rommé, B.; El-Ahmad, Y.; Karlsson, A.; Charrier, V.; Delorme, C.; Ray, A.; Abecassis, P.-Y.; Amara, C.; Vincent, L.; Bonneveaux, H.; Nicolas, J.-P.; Mathieu, M.; Bertrand, T.; Marquette, J.-P.; Michot, N.; Benard, T.; Perrin, M.-A.; Lemaitre, O.; Guerif, S.; Perron, S.; Monget, S.; Gruss-Leleu, F.; Doerflinger, G.; Guizani, H.; Brollo, M.; Delbarre, L.; Bertin, L.; Richepin, P.; Loyau, V.; Garcia-Echevarria, C.; Lengauer, C.; Schio, L. Discovery and Optimization of Pyrimidone Indoline Amide PI3K $\beta$ Inhibitors for the Treatment of Phosphatase and Tensin Homologue (PTEN)-Deficient Cancers. J. Med. Chem. 2014, 57 (3), 903-920.

(18) Shafir, A.; Buchwald, S. L. Highly Selective Room-Temperature Copper-Catalyzed C-N Coupling Reactions. J. Am. Chem. Soc. 2006, 128 (27), 8742-8743. 
